\title{
Dynamic Contrast-Enhanced MR Imaging in Head and Neck Cancer: Techniques and Clinical Applications
}

S. Gaddikeri, R.S. Gaddikeri, T. Tailor, and Y. Anzai

\begin{abstract}
SUMMARY: In the past decade, dynamic contrast-enhanced MR imaging has had an increasing role in assessing the microvascular characteristics of various tumors, including head and neck cancer. Dynamic contrast-enhanced MR imaging allows noninvasive assessment of permeability and blood flow, both important features of tumor hypoxia, which is a marker for treatment resistance for head and neck cancer. Dynamic contrast-enhanced MR imaging has the potential to identify early locoregional recurrence, differentiate metastatic lymph nodes from normal nodes, and predict tumor response to treatment and treatment monitoring in patients with head and neck cancer. Quantitative analysis is in its early stage and standardization and refinement of technique are essential. In this article, we review the techniques of dynamic contrast-enhanced MR imaging data acquisition, analytic methods, current limitations, and clinical applications in head and neck cancer.
\end{abstract}

\begin{abstract}
ABBREVIATIONS: AIF = arterial input function; DCE-MR imaging = dynamic contrast-enhanced MR imaging; EES = extracellular extravascular space; GCA = gadolinium contrast agent; $\mathrm{HNC}=$ head and neck cancer; $\mathrm{K}_{\mathrm{ep}}=$ transfer function from EES to the plasma space; $K^{\text {trans }}=$ volume transfer constant; $\mathrm{V}_{\mathrm{e}}=$ extravascular extracellular volume fraction
\end{abstract}

$H^{\text {end }}$ ead and neck cancer (HNC) accounted for approximately $3 \%$ of all new cancers and $2 \%$ of all cancer-related deaths in 2010 in the United States. ${ }^{1}$ Conventional cross-sectional imaging (CT and MR imaging) plays an important role in assessing locoregional extension of a primary tumor and gross nodal metastases. The shortcomings of conventional imaging include failure to identify early locoregional recurrence, detection of nodal metastasis in normal-sized lymph nodes, prediction of tumor response to treatment, and treatment monitoring in patients with HNC. CT perfusion has been reported to provide vascular information about HNC, though there is increasing concern for exposure to ionizing radiation. ${ }^{2}$ FDGPET is also widely used for initial staging and monitoring response to treatment. However, there is increasing restriction in the number of FDG-PET scans that any patient can undergo during the entire treatment course. ${ }^{3}$

Dynamic contrast-enhanced MR imaging (DCE-MR imag-

From the Department of Radiology (S.G., T.T., Y.A.), University of Washington Medical Center, Seattle, Washington; Department of Neuroradiology (R.S.G.), Rush University, Chicago, Illinois; and Department of Radiology (Y.A.), University of Utah Health Care, Salt Lake City, Utah.

Please address correspondence to Yoshimi Anzai, MD, MPH, Department of Radiology, University of Utah, 30 North 1900 East, 1A071, Salt Lake City, UT 84132; e-mail: yoshimi.anzai@hsc.utah.edu

-- Indicates open access to non-subscribers at www.ajnr.org

三 Indicates article with supplemental on-line table.

http://dx.doi.org/10.3174/ajnr.A4458 ing) is an imaging technique in which rapid sequential MR images are obtained through an area of interest before, during, and after a bolus administration of contrast material. This process allows quantification of various vascular biomarkers, such as blood volume, blood flow, permeability, and wash-in and washout properties.

Angiogenesis (formation of new vessels) is one of the hallmarks of cancer because it is necessary for tumor survival and growth. This process of neoangiogenesis results in tortuous and leaky vessels because the vessel walls in tumor may be discontinuous. ${ }^{4}$ Characteristics of tumor microvasculature include lack of muscularis propria, widened interendothelial junctions, and a discontinuous or absent basement membrane, all of which contribute to increased permeability. ${ }^{4}$ It has been reported that the degree of angiogenesis in a tumor correlates well with tumor biology. ${ }^{5,6}$ Well-differentiated tumors may have near-normal microvasculature, whereas poorly differentiated tumors have disorganized and leaky vessels. ${ }^{5}$ The leaky blood vessels are inefficient in the delivery of oxygen, thus potentially contributing to tumor hypoxia. The process of gadolinium leakage from intravascular-to-extravascular compartments depends on multiple factors such as blood flow to tissue, microvascular attenuation, vascular permeability, and fractional volume of extracellular extravascular space (EES). ${ }^{7}$ These biologic features can be assessed by DCE-MR imaging.

In this article, we review the technical considerations of DCE-MR imaging, qualitative and quantitative analysis, and potential clinical applications in HNC. 


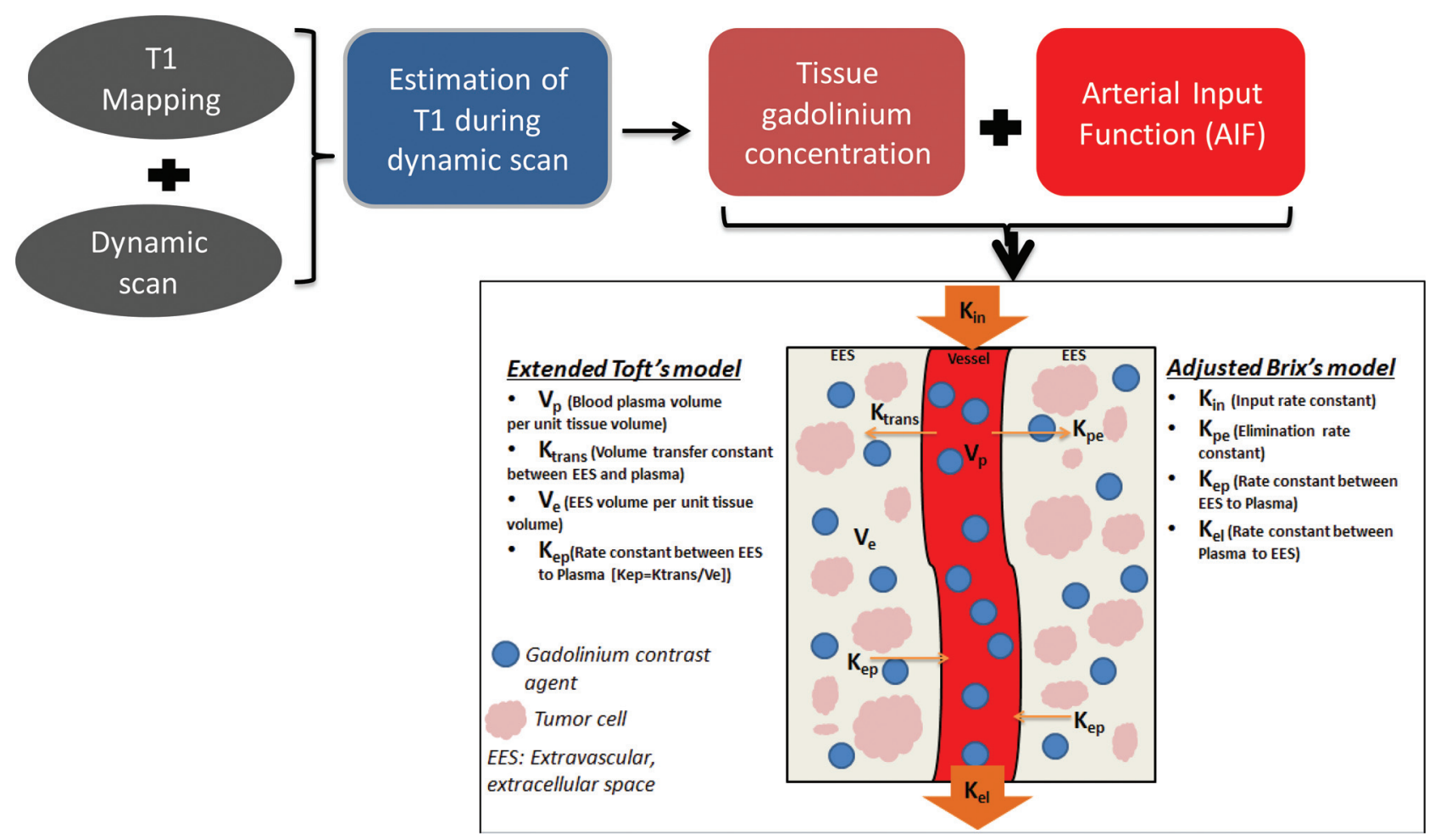

FIG 1. Flow chart demonstrating a typical quantitative method of data analysis. The information from the T1 mapping and dynamic data is used to estimate the changes in $\mathrm{T} 1$ relaxivity during the dynamic scan, which, in turn, provides the information of tissue gadolinium concentration. By fitting the tissue gadolinium concentration and arterial input function data in to commonly used "2-compartment" models (extended Toft or adjusted Brix model), various parameters can be assessed. The difference between the Toft and extended Toft model is the inclusion of assessment of blood plasma volume per unit tissue volume in the later version.

\section{Technique}

Basic Principles of DCE-MR Imaging. Following intravenous administration, gadolinium contrast agent (GCA) travels through the microvasculature and leaks from the intravascular compartment to the EES by passive diffusion, altering signal intensity of the tissue by changing the relaxation rates of water protons. The changes in relaxation and signal depend on how GCA distributes within the tissues. The transfer function from plasma to EES is commonly referred to as volume transfer constant $\left(K^{\text {trans }}\right)$ (Fig 1$)$. As the concentration of intravascular GCA decreases, GCA starts moving from the EES back into the plasma space. The transfer function from EES to the plasma space is referred to as $\left(\mathrm{K}_{\mathrm{ep}}\right)$ (Fig 1). ${ }^{8}$ DCE-MR imaging uses rapid T1-weighted imaging to measure the relaxivity changes resulting from gadolinium leakage in and out of the EES. T1-relaxation is generally assumed to be proportional to the degree of concentration of GCA in the EES. ${ }^{9}$ The timeconcentration curve often reveals the dynamics of GCA accumulation and washout across time. With the knowledge of concentration of GCA (signal intensity) in the EES and vascular compartment (arterial input function $[\mathrm{AIF}]$ ) with time, DCE MR imaging allows quantitative assessment of vascular function in HNC.

\section{Data Acquisition}

The DCE-MR image acquisition consists of 3 steps: 1) a baseline T1 mapping before administration of GCA, 2) dynamic data acquisition, and 3) arterial input function assessment.

Baseline T1 Mapping. To obtain accurate kinetic fitting of DCE-MR imaging data, T1 mapping is critical. ${ }^{10}$ The basic as- sumption for pharmacokinetic modeling of DCE-MR imaging data is that tissue $\mathrm{T} 1$ relaxivity (and hence the signal intensity of tissue) at each time point is directly proportional to the tissue concentration of GCA. ${ }^{11}$ However, this relationship is not always linear because it is influenced by the $\mathrm{T} 1$ characteristics of the native tissue. ${ }^{12}$ To compensate for this nonlinear relationship between signal intensity and tissue GCA concentration, baseline T1 mapping and equilibrium magnetization at each imaging time point are essential. ${ }^{12,13}$ The $\mathrm{T} 1$ values calculated on a voxel-byvoxel basis are termed the $\mathrm{T}_{10}$ map.

Various techniques of imaging data acquisition for T1 mapping are described in the literature, such as variable flip angle techniques (double flip angle versus multiple flip angle), ${ }^{14,15}$ the inversion recovery technique, ${ }^{16,17}$ and the Look-Locker technique. ${ }^{18,19}$ Originally, the Look-Locker technique was reported to have a high degree of accuracy and precision ${ }^{20,21}$ within a reasonable acquisition time, ${ }^{22}$ compared with the conventional inversion recovery technique. ${ }^{23}$ More recently, it has been reported that the multiple flip angle technique provides more accurate and robust $\mathrm{T} 1$ mapping and kinetic parameter estimation than the double flip angle technique. Furthermore, T1 mapping by using multiple flip angles can be obtained with a short scan time without sacrificing signal-to-noise ratio. As such, multiple flip angle T1 mapping is the preferable method of choice for DCE-MR imaging in HNC. ${ }^{24}$

Dynamic Data Acquisition. The dynamic data acquisition follows immediately after baseline T1 mapping. The images are acquired before, during, and after intravenous gadolinium administration. The critical component of high-quality DCE-MR imaging is high 
Table 1: Dynamic sequence at the University of Washington is performed on a 3T scanner

\begin{tabular}{|c|c|c|c|}
\hline Parameters & Philips $^{\mathrm{a}}$ & Siemens ${ }^{b}$ & $\mathrm{GE}^{\mathrm{c}}$ \\
\hline Coil & 16-Channel neurovascular coil & & \\
\hline Parallel imaging & SENSE & iPAT & ASSET \\
\hline Sequence & 3D-TIWI FFE & $\begin{array}{l}\text { 3D-TIWI FISP or } \\
\text { 3D-TIWI FLASH }\end{array}$ & 3D-TTWI FSPGR \\
\hline TR/TE for T1 mapping & $5.2 / 2.5 \mathrm{~ms}$ & & \\
\hline MFA for T1 mapping & $30^{\circ}, 20^{\circ}, 15^{\circ}, 10^{\circ}$, and $2^{\circ}$ & & \\
\hline TR/TE/FA for dynamic imaging & $5.2 / 2.5 \mathrm{~ms} / 5^{\circ}$ & & \\
\hline FOV & $212 \times 149 \mathrm{~mm}^{2}$ & & \\
\hline Voxel & $0.95 / 0.95 / 3.00 \mathrm{~mm}^{3}$ & & \\
\hline Section thickness & $3 \mathrm{~mm}$ & & \\
\hline Signal averaging & NSA: 1 & ACQ: 1 & NEX: 1 \\
\hline $\begin{array}{l}\text { Number of sections per dynamic scan/section } \\
\text { orientation }\end{array}$ & 20/Axial & & \\
\hline Temporal resolution & 3.6 seconds & & \\
\hline Total Tl mapping acquisition time & 26.5 seconds & & \\
\hline Total dynamic acquisition time & 6.10 minutes & & \\
\hline Fat saturation & No & & \\
\hline Contrast injection & $\begin{array}{l}\text { Single dose of } 20-\mathrm{mL} \text { gadoteridol (ProHance }{ }^{\mathrm{d}} \text { ) } \\
\text { injected at a rate of } 5 \mathrm{~mL} / \mathrm{s} \text { through a } \\
\text { peripheral arm vein, followed by a } 20-\mathrm{mL} \\
\text { saline flush with a power injector }\end{array}$ & & \\
\hline
\end{tabular}

Note:-FFE indicates fast-field echo; FSPGR, fast-spoiled gradient recalled; MFA, multiple flip angles; SENSE, sensitivity encoding; iPAT, integrated parallel acquisition technique; ASSET, array spatial sensitivity encoding technique; NSA, number of signal averages; ACQ, acquisitions; FA, flip angle.

a Phillips Healthcare, Best, the Netherlands.

b Siemens, Erlangen, Germany.

${ }^{\mathrm{G}} \mathrm{GE}$ Healthcare, Milwaukee, Wisconsin.

dBracco Diagnostics, Princeton, New Jersey.

Table 2: Commonly used model-free (semiquantitative) parameters for DCE-MRI analysis

\begin{tabular}{lll}
\multicolumn{1}{c}{ Parameter } & \multicolumn{1}{c}{ Definition } & \multicolumn{1}{c}{ Units } \\
\hline Area under curve & Area under the signal intensity or gadolinium dynamic curve & a.u.min or mmol.min/L \\
Relative signal intensity & $\mathrm{S}_{\mathrm{t}} / \mathrm{S}_{0}$ & $\mathrm{NA}$ \\
Initial slope or enhancement slope/rate & Maximum or average slope in the initial enhancement & a.u/min \\
Washout slope/rate & Maximum or average slope in the washout phase & $\mathrm{a} / \mathrm{u} / \mathrm{min}$ \\
$\begin{array}{l}\text { Peak enhancement ratio or maximum signal } \\
\text { enhancement ratio }\end{array}$ & $\left(\mathrm{S}_{\max }-\mathrm{S}_{0}\right) / \mathrm{S}_{0}$ & $\mathrm{NA}$ \\
$T_{\text {max }}$ or time to peak & Time from contrast arrival to peak & $\mathrm{S}$ \\
Maximum intensity-time ratio & PER/T $T_{\max }$ & $\mathrm{S}^{-1}$ \\
\hline
\end{tabular}

Note:- $S_{t}$ indicates MR signal intensity at time $t ; S_{0}$, precontrast signal intensity; $S_{\text {max }}$, maximum signal intensity; a.u, arbitrary unit; min, minute; $P E R$, peak enhancement ratio; $T_{\text {max }}$, time to maximum enhancement; NA, not applicable; $\mathrm{S}$, seconds.

temporal resolution (2-4 seconds). This allows accurate assessment of the hemodynamic process as GCA passes through the microvasculature in the tissue of interest. Higher temporal resolution may compromise SNR and/or coverage (number of sections). The trade-offs among temporal resolution, SNR, and spatial resolution need to be carefully balanced because a reasonable SNR and spatial resolution (in-plane resolution, 0.5-1.7 mm) are required for adequate assessment of tumor vascular function. ${ }^{25}$ The dynamic sequence can be tailored depending on the planned method for data analysis. For example, high spatial resolution with reasonable temporal resolution imaging is sufficient for a "semiquantitative" time-intensity curve analysis, whereas a very high temporal resolution with reasonable spatial resolution is critical for "quantitative" kinetic analysis.

The application of DCE-MR imaging has been reported with both $1.5 \mathrm{~T}$ and $3 \mathrm{~T}$ scanners. ${ }^{26-30}$ Various types of fast $2 \mathrm{D}$ and $3 \mathrm{D}$ T1-weighted sequences have been described, including fast spinecho T1WI, ${ }^{31-34}$ FISP $^{35-40}$ fast-spoiled gradient recalled acquisition, ${ }^{29,41-44}$ turbo fast-field echo, ${ }^{28,45-47}$ and turbo FLASH. ${ }^{48,49}$ Application of parallel imaging for DCE-MR imaging has increased temporal resolution by severalfold, ${ }^{50}$ and thus fast $3 \mathrm{D}$ acquisitions are gradually replacing $2 \mathrm{D}$ acquisitions in DCE-MR imaging. Details of the dynamic sequence practiced at the University of Washington are summarized in Table 1.

Arterial Input Function. Another crucial component of DCE-MR imaging is the assessment of an AIF. The AIF estimates the rate of change in the concentration of contrast in the plasma (vascular space) with time. An accurate AIF is essential for quantitative analysis of dynamic data by using any of the currently available analytic methods. Generally, AIF is commonly obtained from the dynamic dataset. ${ }^{51-53}$ The changes in signal intensity during the passage of GCA can be measured simultaneously in both the blood vessels and the tissue of interest. AIF allows conversion of the blood plasma signal intensity to intravascular contrast agent concentration on implementation of a calibration algorithm. Any visible large artery within an area of interest can be selected for AIF with the dynamic dataset. For HNC imaging with DCE-MR imaging, the carotid and vertebral arteries are well-suited for AIF selection because they run along the long axis of the neck and are of relatively large caliber. ${ }^{54}$ 
Table 3: Commonly used quantitative parameters in the DCE-MRI pharmacokinetic analysis

\begin{tabular}{lll}
\hline Parameter & \multicolumn{1}{c}{ Definition } & Units \\
\hline$K^{\text {trans }}$ & Volume transfer constant between EES and blood plasma & $\mathrm{Min}^{-1}$ \\
$V_{e}$ & EES volume per unit tissue volume & $\mathrm{NA}$ \\
$\mathrm{V}_{\mathrm{p}}$ & Blood plasma volume per unit tissue volume & $\mathrm{NA}$ \\
$\mathrm{K}_{\mathrm{ep}}$ or $\mathrm{K}_{21}$ & Rate constant from EES to blood plasma & $\mathrm{Min}^{-1}$ \\
$\mathrm{~K}_{\mathrm{pe}}$ or $\mathrm{K}_{12}$ & Rate constant from blood plasma to EES & $\mathrm{Min}^{-1}$ \\
$\mathrm{~K}_{\mathrm{el}}$ & Elimination rate constant & $\mathrm{Min}^{-1}$ \\
$\mathrm{Amp}$ or $\mathrm{AH}$ & Amplitude of the normalized dynamic curve & $\mathrm{NA}$ \\
\hline
\end{tabular}

Note:-Amp or AH, amplitude of the normalized dynamic curve; NA, not applicable; Min, minute.
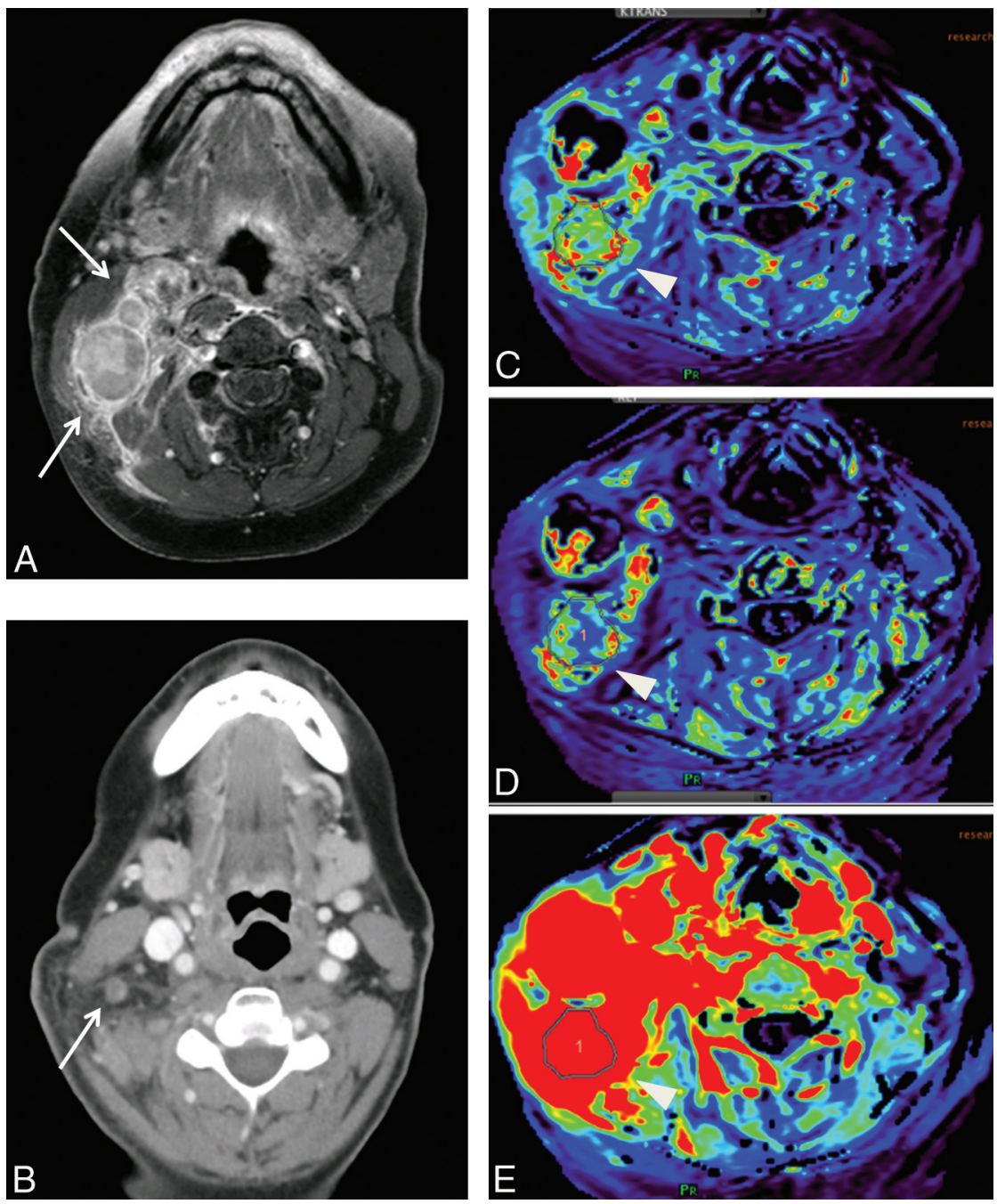

FIG 2. A 57-year-old male patient with T2N3bM0 undifferentiated nasopharyngeal cancer. Pretreatment gadolinium-enhanced axial T7-weighted MR imaging of the neck demonstrates metastatic right level IIb lymph nodes $(A)$. Parametric maps (C, D, and $E$ ) show higher volume transfer constant $\left(K^{\text {trans }}=0.26 / \mathrm{min}\right), \mathrm{K}_{\mathrm{ep}}$, and area under curve, respectively. Axial contrast-enhanced neck CT at 6 months post-chemoradiation treatment demonstrates a favorable response to treatment $(B)$

\section{Data Analysis}

DCE-MR imaging is commonly analyzed with semiquantitative analysis or quantitative analysis.

\section{Semiquantitative Method}

The semiquantitative method is a model-free analysis by using the observed data points on a time-intensity curve. It is a simple and easily implementable method by using commercially available software. ${ }^{31,35-41,44,55-58}$ Commonly calculated pa- rameters on the time-intensity curve are listed in Table 2. The time-intensity curve obtained following placement of an ROI on the tumor provides a rough estimate of how fast the GCA enters and exits the tumor. It has been reported that malignant tumors have a longer time to peak and lower relative maximum enhancement compared with benign lesions in the head and neck. ${ }^{59}$ The prolonged time to peak and lower relative maximum enhancement were also noted in metastatic lymph nodes compared with benign lymph nodes among patients with HNC. ${ }^{42}$ The limitation of this semiquantitative analysis is that the semiquantitative parameters do not necessarily have physical correlates; rather, they may represent mixed measures. For example, the area under curve is a combination of tissue blood flow vascular permeability and fractional interstitial space and is, therefore, not an accurate estimate of blood volume. Therefore, the physiologic meanings of these parameters remain ambiguous as to what biologic property they represent. $^{25}$

\section{Quantitative Methods}

Quantitative analysis of DCE-MR imaging data is based on the generalized pharmacokinetic models. The 2 most important assumptions of these models are the following: 1) GCA is distributed in $\geq 1$ compartment of the human body, and 2) distribution of the contrast agent in a particular compartment is uniform.

A typical quantitative method of data analysis is outlined in the flow chart (Fig 1). The most frequently used pharmacokinetic models in head and neck DCE-MR imaging data analysis include the Toft and Kermode model (Toft model), ${ }^{29,30,45,60,61}$ the Brix model, ${ }^{28,34}$ and their modifications (Fig 1). These are based on the assumption of a " 2 compartment model," in which the GCA is distributed into the "central" and "peripheral" compartments. The central compartment consists of intravascular extracellular volume fraction (blood plasma), and the peripheral compartment consists of extravascular extracellular volume fraction $\left(\mathrm{V}_{\mathrm{e}}\right)$. The Toft model generally requires the knowledge of AIF and T1 mapping for accurate assessment of quantitative parameters. Fitting the DCE-MR imaging data into 1 of these models allows estimation of various model-base parameters, which potentially aids in the understanding of tumor physiol- 

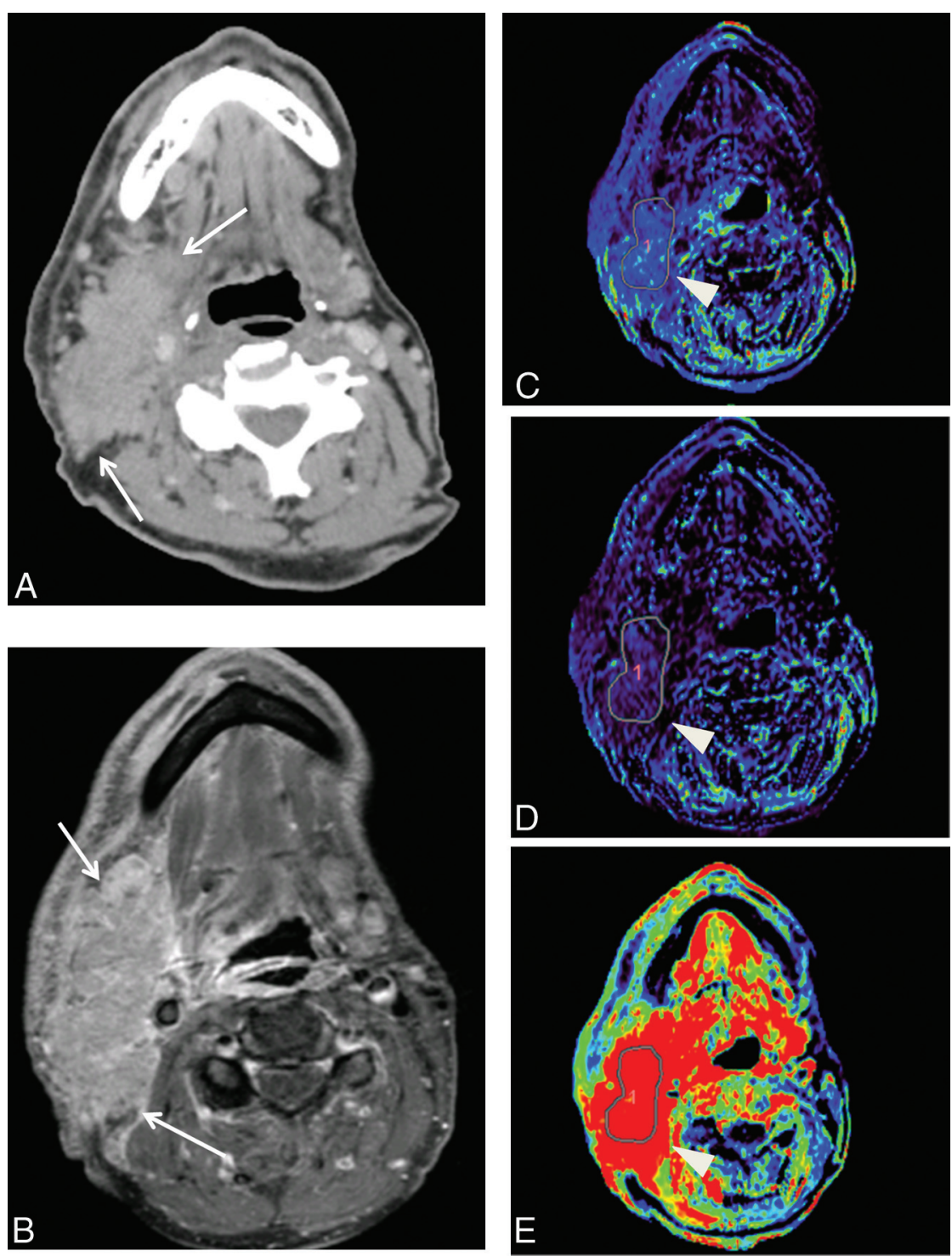

FIG 3. A 52-year-old male patient with squamous cell carcinoma of the right palatine tonsil. Pretreatment axial contrast-enhanced neck CT demonstrates metastatic right level II lymph nodes (A). Parametric maps $\left(C, D\right.$, and $E$ ) show a lower volume transfer constant $\left(K^{\text {trans }}=0.06 / \mathrm{min}\right), \mathrm{K}_{\mathrm{ep}}$, and area under curve, respectively. Gadolinium-enhanced axial T1-weighted MR imaging of the neck at 12 months post-chemoradiation treatment demonstrates an unfavorable response to treatment $(B)$. oxygen or chemotherapy drugs to the tissue. In addition, this inefficiency causes increased interstitial fluid pressure, which ultimately reduces tumor perfusion, further facilitating tumor hypoxia. ${ }^{64}$ Although a study by Newbold indicated that tumors with higher $K^{\text {trans }}$ were associated with hypoxia defined by pimonidazole and carbonic anhydrase staining, and hence poor outcome, ${ }^{46}$ others reported that tumors with lower $K^{\text {trans }}$ were associated with poor response. ${ }^{27,29,61,65} K^{\text {trans }}$ generally reflects a combination of perfusion and permeability. Lower Kep is also reported to correlate with poor response to treatment. ${ }^{61}$ A tumor with higher $K^{\text {trans }}$, highly perfused tumor has higher oxygenation, better delivery of chemotherapeutic drugs, likely explaining improved treatment response. ${ }^{66-67}$ Skewness of $K^{\text {trans }}$ is also reported to predict treatment response, that a tumor with larger skewed $K^{\text {trans }}$ has a worse prognosis potentially reflecting tumor heterogeneity. $^{29}$

DCE-MR imaging has been reported to be useful for various applications in HNC imaging, such as differentiating squamous cell carcinoma from lymphoma and undifferentiated carcinomas, ${ }^{68}$ detecting metastatic lymph nodes, ${ }^{42}$ assessing tumor cell proliferation and microvessel attenuation, ${ }^{55,69}$ and predicting early treatment response and treatment outcome. ${ }^{27-29,41,46,61}$

We searched MEDLINE, PubMed, and Google for the literature published during the most recent 6-year interval (2008-2013) containing all of the following: DCE-MR imaging, HNC, and ogy and pathology. ${ }^{62}$ Frequently used parameters that can be obtained from quantitative DCE-MR imaging data are summarized in Table 3.

Quantitative methods of data analysis provide parameters quantifying microvasculature physiology and tumor biology. Additionally, the model-based parameters are more precise and reproducible and are reported to be independent of scanners and tissue type. ${ }^{63}$ Hence, these parameters may be potentially useful for sequential follow-up to determine treatment response in an individual patient and also as biologic markers for predicting and monitoring the therapeutic efficacy in multicenter trials.

\section{Clinical Applications of DCE-MR Imaging in Head and Neck Cancer}

One of the most exciting aspects of DCE-MR imaging application in HNC is its potential to serve as an imaging biomarker for hypoxia. The abnormal tumor vessels are inefficient in the delivering quantitative (model-based) analysis of dynamic data for pretreatment assessment and/or monitoring treatment response. The Online Table summarizes various studies in the literature and their respective contributions to DCE-MR imaging of HNC by using various quantitative methods. Early assessment of treatment response is critical for advanced head and neck cancers. The question remains as to whether pretreatment measures of DCE parameters suffice to address the treatment response or it is necessary to measure changes in DCE parameters to access treatment response. Figs 2 and 3 demonstrate 2 patients with HNC with nodal metastasis exhibiting different responses to chemoradiation.

\section{Challenges}

DCE-MR imaging of HNC is clearly in its early stage. Substantial variability exists in quantification methods, parameter choice, 
and analytic methods. Many factors in the data acquisition and analysis can affect the reliability of results in DCE-MR imaging studies. For example, the accuracy and precision of the pharmacokinetic parameter estimates are largely determined by SNR, temporal resolution of the MR image, AIF, and estimation of T1 mapping. ${ }^{70}$ Systematic errors can be introduced from various sources, such as the breakdown of linearity in the gadolinium concentration calibration curve and inaccuracy of T1 mapping. ${ }^{71,72}$

Standardization of data acquisition and analysis will facilitate the translation of DCE-MR imaging to clinical settings, in particular to multicenter clinical trials. ${ }^{73}$ The DCE-MR imaging subcommittee of the Radiological Society of North America Quantitative Imaging Biomarkers Alliance initiative provides guidelines for data acquisition, analysis, and quality control on 1.5T systems. The image intensity should be converted to gadolinium concentration through the use of a multiple flip angle precontrast T1 map after corrections for patient motion, B1 field inhomogeneity, and coil sensitivity. ${ }^{74}$ The pharmacokinetic parameter $K^{\text {trans }}$ (Toft model) and area under curve (model-free parameter) are recommended as standard quantitative end points that should be used in clinical trials and practice.

Another challenge with DCE-MR imaging parameters is validation with tumor histology and hypoxia. A potential reason includes tumor heterogeneity at the subvoxel level. Therefore, some authors suggest that DCE-MR imaging parameters may be better validated with immunohistochemical measurements averaged over several fields randomly picked from the ROI. ${ }^{73}$

\section{CONCLUSIONS}

Although DCE-MR imaging has the potential to provide biologic information of tumor angiogenesis and vascular function in HNC, its technical development is still in an early stage. The standardization of image acquisition and data analysis is critical to moving forward with a multicenter head and neck tumor registry and in determining the clinical role of DCE-MR imaging in head and neck oncologic imaging.

Disclosures: Tina Tailor—RELATED: Grant: American Society of Head and Neck Radiology, William N. Hanafee Award.

\section{REFERENCES}

1. Jemal A, Bray F, Center MM, et al. Global cancer statistics. CA Cancer J Clin 2011;61:69-90 CrossRef Medline

2. Razek AA, Tawfik AM, Elsorogy LG, et al. Perfusion CT of head and neck cancer. Eur J Radiol 2014;83:537-44 CrossRef Medline

3. Bussink J, van Herpen CM, Kaanders JH, et al. PET-CT for response assessment and treatment adaptation in head and neck cancer. Lancet Oncol 2010;11:661-69 CrossRef Medline

4. Carmeliet P, Jain RK. Angiogenesis in cancer and other diseases. Nature 2000;407:249-57 CrossRef Medline

5. Kaur B, Tan C, Brat DJ, et al. Genetic and hypoxic regulation of angiogenesis in gliomas. J Neurooncol 2004;70:229-43 CrossRef Medline

6. Patankar TF, Haroon HA, Mills SJ, et al. Is volume transfer coefficient ( $\mathrm{K}($ trans $))$ related to histologic grade in human gliomas? AJNR Am J Neuroradiol 2005;26:2455-65 Medline

7. Paldino MJ, Barboriak DP. Fundamentals of quantitative dynamic contrast-enhanced MR imaging. Magn Reson Imaging Clin N Am 2009;17:277-89 CrossRef Medline
8. Knopp MV, Weiss E, Sinn HP, et al. Pathophysiologic basis of contrast enhancement in breast tumors. J Magn Reson Imaging 1999;10: 260-66 Medline

9. Cheng HL. Investigation and optimization of parameter accuracy in dynamic contrast-enhanced MRI. J Magn Reson Imaging 2008;28: 736-43 CrossRef Medline

10. Di Giovanni P, Azlan CA, Ahearn TS, et al. The accuracy of pharmacokinetic parameter measurement in DCE-MRI of the breast at $3 \mathrm{~T}$. Phys Med Boil 2010;55:121-32 CrossRef

11. Brix G, Semmler W, Port R, et al. Pharmacokinetic parameters in CNS Gd-DTPA enhanced MR imaging. J Comput Assist Tomogr 1991;15:621-28 CrossRef Medline

12. Evelhoch JL. Key factors in the acquisition of contrast kinetic data for oncology. J Magn Reson Imaging 1999;10:254-59 Medline

13. Leach MO, Brindle KM, Evelhoch JL, et al; Pharmacodynamic/Pharmacokinetic Technologies Advisory Committee, Drug Development Office, Cancer Research UK. The assessment of antiangiogenic and antivascular therapies in early-stage clinical trials using magnetic resonance imaging: issues and recommendations. Br J Cancer 2005; 92:1599-610 CrossRef Medline

14. Wang HZ, Riederer SJ, Lee JN. Optimizing the precision in T1 relaxation estimation using limited flip angles. Magn Reson Med 1987;5: 399-416 CrossRef Medline

15. Deoni SC, Rutt BK, Peters TM. Rapid combined T1 and T2 mapping using gradient recalled acquisition in the steady state. Magn Reson Med 2003;49:515-26 CrossRef Medline

16. Jahng GH, Stables L, Ebel A, et al. Sensitive and fast T1 mapping based on two inversion recovery images and a reference image. Med Phys 2005;32:1524-28 CrossRef Medline

17. Ogg RJ, Kingsley PB. Optimized precision of inversion-recovery T1 measurements for constrained scan time. Magn Reson Med 2004;51: 625-30 CrossRef Medline

18. Karlsson M, Nordell B. Analysis of the Look-Locker T(1) mapping sequence in dynamic contrast uptake studies: simulation and in vivo validation. Magn Reson Imaging 2000;18:947-54 CrossRef Medline

19. Freeman AJ, Gowland PA, Mansfield P. Optimization of the ultrafast Look-Locker echo-planar imaging T1 mapping sequence. Magn Reson Imaging 1998;16:765-72 CrossRef Medline

20. Brix G, Schad LR, Deimling M, et al. Fast and precise T1 imaging using a TOMROP sequence. Magn Reson Imaging 1990;8:351-56 CrossRef Medline

21. Kay I, Henkelman RM. Practical implementation and optimization of one-shot T1 imaging. Magn Reson Med 1991;22:414-24 CrossRef Medline

22. Henderson E, McKinnon G, Lee TY, et al. A fast 3D Look-Locker method for volumetric T1 mapping. Magn Reson Imaging 1999;17: 1163-71 CrossRef Medline

23. Crawley AP, Henkelman RM. A comparison of one-shot and recovery methods in T1 imaging. Magn Reson Med 1988;7:23-34 CrossRef Medline

24. Yuan J, Chow SK, Yeung DK, et al. Quantitative evaluation of dualflip-angle T1 mapping on DCE-MRI kinetic parameter estimation in head and neck. Quant Imaging Med Surg 2012;2:245-53 CrossRef Medline

25. Yankeelov TE, Gore JC. Dynamic contrast enhanced magnetic resonance imaging in oncology: theory, data acquisition, analysis, and examples. Curr Med Imaging Rev 2009;3:91-107 Medline

26. Chawla S, Kim S, Dougherty L, et al. Pretreatment diffusionweighted and dynamic contrast-enhanced MRI for prediction of local treatment response in squamous cell carcinomas of the head and neck. AJR Am J Roentgenol 2013;200:35-43 CrossRef Medline

27. Chawla S, Kim S, Loevner LA, et al. Prediction of disease-free survival in patients with squamous cell carcinomas of the head and neck using dynamic contrast-enhanced MR imaging. AJNR Am J Neuroradiol 2011;32:778-84 CrossRef Medline

28. Chikui T, Kawano S, Kawazu T, et al. Prediction and monitoring of the response to chemoradiotherapy in oral squamous cell carcino- 
mas using a pharmacokinetic analysis based on the dynamic contrast-enhanced MR imaging findings. Eur Radiol 2011;21:1699-708 CrossRef Medline

29. Shukla-Dave A, Lee NY, Jansen JF, et al. Dynamic contrast-enhanced magnetic resonance imaging as a predictor of outcome in headand-neck squamous cell carcinoma patients with nodal metastases. Int J Radiat Oncol Boil Phys 2012;82:1837-44 CrossRef

30. Wang P, Popovtzer A, Eisbruch A, et al. An approach to identify, from DCE MRI, significant subvolumes of tumors related to outcomes in advanced head-and-neck cancer. Med Phys 2012;39: 5277-85 CrossRef Medline

31. Yabuuchi H, Fukuya T, Tajima T, et al. Salivary gland tumors: diagnostic value of gadolinium-enhanced dynamic MR imaging with histopathologic correlation. Radiology 2003;226:345-54 CrossRef Medline

32. Yabuuchi $\mathrm{H}$, Matsuo $\mathrm{Y}$, Kamitani T, et al. Parotid gland tumors: can addition of diffusion-weighted MR imaging to dynamic contrastenhanced MR imaging improve diagnostic accuracy in characterization? Radiology 2008;249:909-16 CrossRef Medline

33. Tunca F, Giles Y, Salmaslioglu A, et al. The preoperative exclusion of thyroid carcinoma in multinodular goiter: dynamic contrast-enhanced magnetic resonance imaging versus ultrasonographyguided fine-needle aspiration biopsy. Surgery 2007;142:992-1002; discussion 1002.e1001-1002 CrossRef Medline

34. Juan CJ, Chen CY, Jen YM, et al. Perfusion characteristics of late radiation injury of parotid glands: quantitative evaluation with dynamic contrast-enhanced MRI. Eur Radiol 2009;19:94-102 CrossRef Medline

35. Asaumi J, Hisatomi M, Yanagi Y, et al. Assessment of ameloblastomas using MRI and dynamic contrast-enhanced MRI. Eur J Radiol 2005;56:25-30 CrossRef Medline

36. Asaumi J, Yanagi Y, Hisatomi M, et al. The value of dynamic contrast-enhanced MRI in diagnosis of malignant lymphoma of the head and neck. Eur J Radiol 2003;48:183-87 CrossRef Medline

37. Asaumi J, Yanagi Y, Konouchi H, et al. Application of dynamic contrast-enhanced MRI to differentiate malignant lymphoma from squamous cell carcinoma in the head and neck. Oral Oncol 2004;40: 579-84 CrossRef Medline

38. Hisatomi M, Asaumi J, Yanagi Y, et al. Assessment of pleomorphic adenomas using MRI and dynamic contrast enhanced MRI. Oral Oncol 2003;39:574-79 CrossRef Medline

39. Matsuzaki H, Hara M, Yanagi Y, et al. Magnetic resonance imaging (MRI) and dynamic MRI evaluation of extranodal non-Hodgkin lymphoma in oral and maxillofacial regions. Oral Surg Oral Med Oral Pathol Oral Radiol 2012;113:126-33 CrossRef Medline

40. Unetsubo T, Konouchi H, Yanagi Y, et al. Dynamic contrast-enhanced magnetic resonance imaging for estimating tumor proliferation and microvessel density of oral squamous cell carcinomas. Oral Oncol 2009;45:621-26 CrossRef Medline

41. Agrawal S, Awasthi R, Singh A, et al. An exploratory study into the role of dynamic contrast-enhanced (DCE) MRI metrics as predictors of response in head and neck cancers. Clin Radiol 2012;67:e1-5 CrossRef Medline

42. Fischbein NJ, Noworolski SM, Henry RG, et al. Assessment of metastatic cervical adenopathy using dynamic contrast-enhanced MR imaging. AJNR Am J Neuroradiol 2003;24:301-11 Medline

43. Noworolski SM, Fischbein NJ, Kaplan MJ, et al. Challenges in dynamic contrast-enhanced MRI imaging of cervical lymph nodes to detect metastatic disease. J Magn Reson Imaging 2003;17:455-62 CrossRef Medline

44. Yuan Y, Kuai XP, Chen XS, et al. Assessment of dynamic contrastenhanced magnetic resonance imaging in the differentiation of malignant from benign orbital masses. Eur J Radiol 2013;82:1506-11 CrossRef Medline

45. Chikui T, Kitamoto E, Kawano S, et al. Pharmacokinetic analysis based on dynamic contrast-enhanced MRI for evaluating tumor response to preoperative therapy for oral cancer. J Magn Reson Imaging 2012;36:589-97 CrossRef Medline
46. Newbold K, Castellano I, Charles-Edwards E, et al. An exploratory study into the role of dynamic contrast-enhanced magnetic resonance imaging or perfusion computed tomography for detection of intratumoral hypoxia in head-and-neck cancer. Int J Radiat Oncol Boil Phys 2009;74:29-37 CrossRef Medline

47. Yuan J, Chow SK, Yeung DK, et al. A five-colour colour-coded mapping method for DCE-MRI analysis of head and neck tumours. Clin Radiol 2012;67:216-23 CrossRef Medline

48. Støre G, Smith HJ, Larheim TA. Dynamic MR imaging of mandibular osteoradionecrosis. Acta Radiol 2000;41:31-37 CrossRef Medline

49. Van Cann EM, Rijpkema M, Heerschap A, et al. Quantitative dynamic contrast-enhanced MRI for the assessment of mandibular invasion by squamous cell carcinoma. Oral Oncol 2008;44:1147-54 CrossRef Medline

50. Tsao J, Boesiger P, Pruessmann KP. k-t BLAST and k-t SENSE: dynamic MRI with high frame rate exploiting spatiotemporal correlations. Magn Reson Med 2003;50:1031-42 CrossRef Medline

51. Port RE, Knopp MV, Hoffmann U, et al. Multicompartment analysis of gadolinium chelate kinetics: blood-tissue exchange in mammary tumors as monitored by dynamic MR imaging. J Magn Reson Imaging 1999;10:233-41 Medline

52. van Osch MJ, Vonken EJ, Viergever MA, et al. Measuring the arterial input function with gradient echo sequences. Magn Reson Med 2003;49:1067-76 CrossRef Medline

53. McIntyre DJ, Ludwig C, Pasan A, et al. A method for interleaved acquisition of a vascular input function for dynamic contrast-enhanced MRI in experimental rat tumours. NMR Biomed 2004;17: 132-43 CrossRef Medline

54. Kim YR, Rebro KJ, Schmainda KM. Water exchange and inflow affect the accuracy of T1-GRE blood volume measurements: implications for the evaluation of tumor angiogenesis. Magn Reson Med 2002;47:1110-20 CrossRef Medline

55. Konouchi H, Asaumi Ji, Yanagi Y, et al. Evaluation of tumor proliferation using dynamic contrast enhanced-MRI of oral cavity and oropharyngeal squamous cell carcinoma. Oral Oncol 2003;39: 290-95 CrossRef Medline

56. Matsuzaki H, Yanagi Y, Hara M, et al. Minor salivary gland tumors in the oral cavity: diagnostic value of dynamic contrast-enhanced MRI. Eur J Radiol 2012;81:2684-91 CrossRef Medline

57. Matsuzaki H, Yanagi Y, Hara M, et al. Diagnostic value of dynamic contrast-enhanced MRI for submucosal palatal tumors. Eur J Radiol 2012;81:3306-12 CrossRef Medline

58. Yuan Y, Yue XH, Tao XF. The diagnostic value of dynamic contrastenhanced MRI for thyroid tumors. Eur J Radiol 2012;81:3313-18 CrossRef Medline

59. Furukawa M, Parvathaneni U, Maravilla K, et al. Dynamic contrastenhanced MR perfusion imaging of head and neck tumors at $3 \mathrm{Te}-$ sla. Head Neck. 2013;35:923-29 CrossRef Medline

60. Jansen JF, Schöder H, Lee NY, et al. Tumor metabolism and perfusion in head and neck squamous cell carcinoma: pretreatment multimodality imaging with $1 \mathrm{H}$ magnetic resonance spectroscopy, dynamic contrast-enhanced MRI, and [18F]FDG-PET. Int J Radiat Oncol Boil Phys 2012;82:299-307 CrossRef

61. Jansen JF, Schöder H, Lee NY, et al. Noninvasive assessment of tumor microenvironment using dynamic contrast-enhanced magnetic resonance imaging and $18 \mathrm{~F}$-fluoromisonidazole positron emission tomography imaging in neck nodal metastases. Int $\mathrm{J} \mathrm{Ra}$ diat Oncol Boil Phys 2010;77:1403-10 CrossRef Medline

62. Taylor JS, Tofts PS, Port R, et al. MR imaging of tumor microcirculation: promise for the new millennium. J Magn Reson Imaging 1999;10:903-07 Medline

63. Jackson A, O'Connor JP, Parker GJ, et al. Imaging tumor vascular heterogeneity and angiogenesis using dynamic contrast-enhanced magnetic resonance imaging. Clin Cancer Res 2007;13:3449-59 CrossRef Medline

64. Fukumura D, Jain RK. Tumor microenvironment abnormalities: causes, consequences, and strategies to normalize. J Cell Biochem 2007;101:937-49 CrossRef Medline 
65. Kim S, Loevner LA, Quon H, et al. Prediction of response to chemoradiation therapy in squamous cell carcinomas of the head and neck using dynamic contrast-enhanced MR imaging. AJNR Am J Neuroradiol 2010;31:262-68 CrossRef Medline

66. Tofts PS, Brix G, Buckley DL, et al. Estimating kinetic parameters from dynamic contrast-enhanced T(1)-weighted MRI of a diffusable tracer: standardized quantities and symbols. J Magn Reson Imaging 1999;10:223-32 Medline

67. Miller JC, Pien HH, Sahani D, et al. Imaging angiogenesis: applications and potential for drug development. J Natl Cancer Inst 2005; 97:172-87 CrossRef Medline

68. Lee FK, King AD, Ma BB, et al. Dynamic contrast enhancement magnetic resonance imaging (DCE-MRI) for differential diagnosis in head and neck cancers. Eur J Radiol 2012;81:784-88 CrossRef Medline

69. Tuncbilek N, Karakas HM, Altaner S. Dynamic MRI in indirect estimation of microvessel density, histologic grade, and prognosis in colorectal adenocarcinomas. Abdom Imaging 2004;29:166-72 CrossRef Medline

70. Henderson E, Rutt BK, Lee TY. Temporal sampling requirements for the tracer kinetics modeling of breast disease. Magn Reson Imaging 1998;16:1057-73 CrossRef Medline

71. Larsson HB, Stubgaard M, Søndergaard L, et al. In vivo quantification of the unidirectional influx constant for Gd-DTPA diffusion across the myocardial capillaries with MR imaging. J Magn Reson Imaging 1994;4:433-40 CrossRef Medline

72. Tofts PS. Modeling tracer kinetics in dynamic Gd-DTPA MR imaging. J Magn Reson Imaging 1997;7:91-101 CrossRef Medline

73. Yang X, Knopp MV. Quantifying tumor vascular heterogeneity with dynamic contrast-enhanced magnetic resonance imaging: a review. J Biomed Biotechnol 2011;2011:732848 CrossRef Medline

74. Singh A, Haris M, Rathore D, et al. Quantification of physiological and hemodynamic indices using $\mathrm{T}(1)$ dynamic contrast-enhanced MRI in intracranial mass lesions. J Magn Reson Imaging 2007;26: 871-80 CrossRef Medline

75. Jansen JF, Carlson DL, Lu Y, et al. Correlation of a priori DCE-MRI and (1)H-MRS data with molecular markers in neck nodal metastases: initial analysis. Oral Oncol 2012;48:717-22 CrossRef Medline 